\title{
ANÁLISE MORFOLÓGICA DO ESMALTE E DA DENTINA APÓS O USO DE DOIS TIPOS DE SISTEMAS ADESIVOS
}

\author{
Lorena Silva da Cruz; ; Gardenia Mascarenhas Oliveira ${ }^{2}$ \\ 1. Bolsista PROBIC/UEFS, Graduanda em Odontologia, Universidade Estadual de Feira de Santana, e-mail: \\ lorycruz10@hotmail.com \\ 2. Orientadora, Departamento de Saúde, Universidade Estadual de Feira de Santana, e-mail: \\ gardeniamascarenhas@uol.com.br
}

PALAVRAS-CHAVE: adesivos, camada híbrida, aderência dental

\section{INTRODUÇÃO}

A odontologia moderna tem como premissa básica a realização de procedimentos minimamente invasivos e estéticos. O início dessa mudança ocorreu com Buonocore (1955), que melhorou a adesão de uma resina acrílica ao esmalte através do condicionamento com ácido fosfórico a 85\%. Este estudo clássico abriu perspectivas para o entendimento da adesividade no que se refere à biologia do substrato dentário e o seu comportamento, frente aos novos materiais e técnicas introduzidas na prática clínica. Por conta da homogeneidade da superfície do esmalte, a adesão a esse substrato é efetiva e duradoura (FRANKENBERGER; KRÄMER; PETSCHELT, 2000). Em contrapartida, a união à dentina ainda é um desafio, já que ela se apresenta como um substrato heterogêneo e naturalmente úmido, o que torna o procedimento de adesão altamente sensível (KHOROUSHI; RAFIZADEH; SAMIMI, 2014). De acordo com Inoue et al (2003) existem adesivos convencionais, de 3 ou 2 passos; e autocondicionantes de 2 passos ou passo único. Apesar de os adesivos autocondicionantes apresentarem monômeros ácidos, é recomendado que seja feito o condicionamento seletivo do esmalte com ácido fosfórico a 37\% como forma de melhorar a efetividade adesiva (SZESZ et al., 2016; COPPINI et al., 2017). Sistemas adesivos universais têm sido desenvolvidos com a proposta de serem utilizadas técnicas de condicionamento ácido total, seletivo em esmalte, ou autocondicionante (TAKAMIZAWA et al., 2016).

Diante da variedade de propostas de tratamento, o objetivo deste estudo foi avaliar, através de microscopia eletrônica de varredura, a morfologia do esmalte e da dentina, utilizando um sistema adesivo universal, com as técnicas de condicionamento total e autocondicionante em esmalte, e um sistema adesivo autocondicionante, utilizado com a técnica de condicionamento seletivo em esmalte.

\section{METODOLOGIA}

As superfícies vestibulares de dezoito terceiros molares inferiores humanos foram cortadas longitudinalmente utilizando-se discos de carborundum em baixa rotação, ao nível do sulco vestíbulo-lingual, e montadas em stubs metálicos. As cavidades foram preparadas com broca $\mathrm{n}^{\circ} 330$ em alta rotação, padronizadas com: Profundidade em esmalte $-1 \mathrm{~mm}$; Profundidade em dentina $-2 \mathrm{~mm}$; Dimensão mésio-distal $-3 \mathrm{~mm}$; Dimensão ocluso-cervical $-2 \mathrm{~mm}$. As amostras foram aleatoriamente divididas em 9 grupos $(n=2)$, porém uma amostra de cada grupo foi perdida devido a excesso de desidratação, restando metade das amostras $(n=1)$, sendo os grupos de 1 a 4 os grupos 
controle. Os grupos 1 (esmalte) e 02 (dentina) não tiveram nenhum tratamento; os grupos 3 (esmalte) e 4 (dentina) foram tratados com ácido fosfórico a 37\%; os grupos 5 a 7 foram superfícies de esmalte tratadas com ácido fosfórico a 37\% + Sistema Single Bond Universal, apenas sistema Single Bond Universal, e ácido fosfórico a $37 \%+$ Sistema Clearfil SE, respectivamente; e os grupos 8 e 9 foram superfícies de dentina tratadas com ácido fosfórico a 37\% + sistema Single Bond Universal, e apenas sistema Clearfil SE, respectivamente. As amostras de cada grupo foram observadas no monitor do microscópio eletrônico de varredura e microfotografadas com aumentos de 1000, 2000 e 4000 vezes. As fotomicrografias foram analisadas de forma comparativa com a finalidade de avaliar o padrão de adesividade conseguido com os dois sistemas adesivos, empregados com técnicas diferentes, em cada superfície.

\section{RESULTADOS E DISCUSSÃO}

Durante o preparo cavitário, são liberadas partículas de gordura, saliva, sangue, colágeno, e hidroxiapatita, que juntos formam uma camada de detritos orgânicos e inorgânicos, ou smear layer (PASHLEY; MICHELICH; KEHL, 1981), visualizada na Figura 1.A e 1.D. Ela provoca diminuição na permeabilidade e dificuldade de acesso à dentina subjacente. $\mathrm{O}$ condicionamento com ácido fosfórico na dentina promove a abertura dos túbulos dentinários (Figuras 1.E e 1.F), aumentando sua permeabilidade, proporcionando uma boa adesão (ODA; MATOS; LIBERTI, 1999).
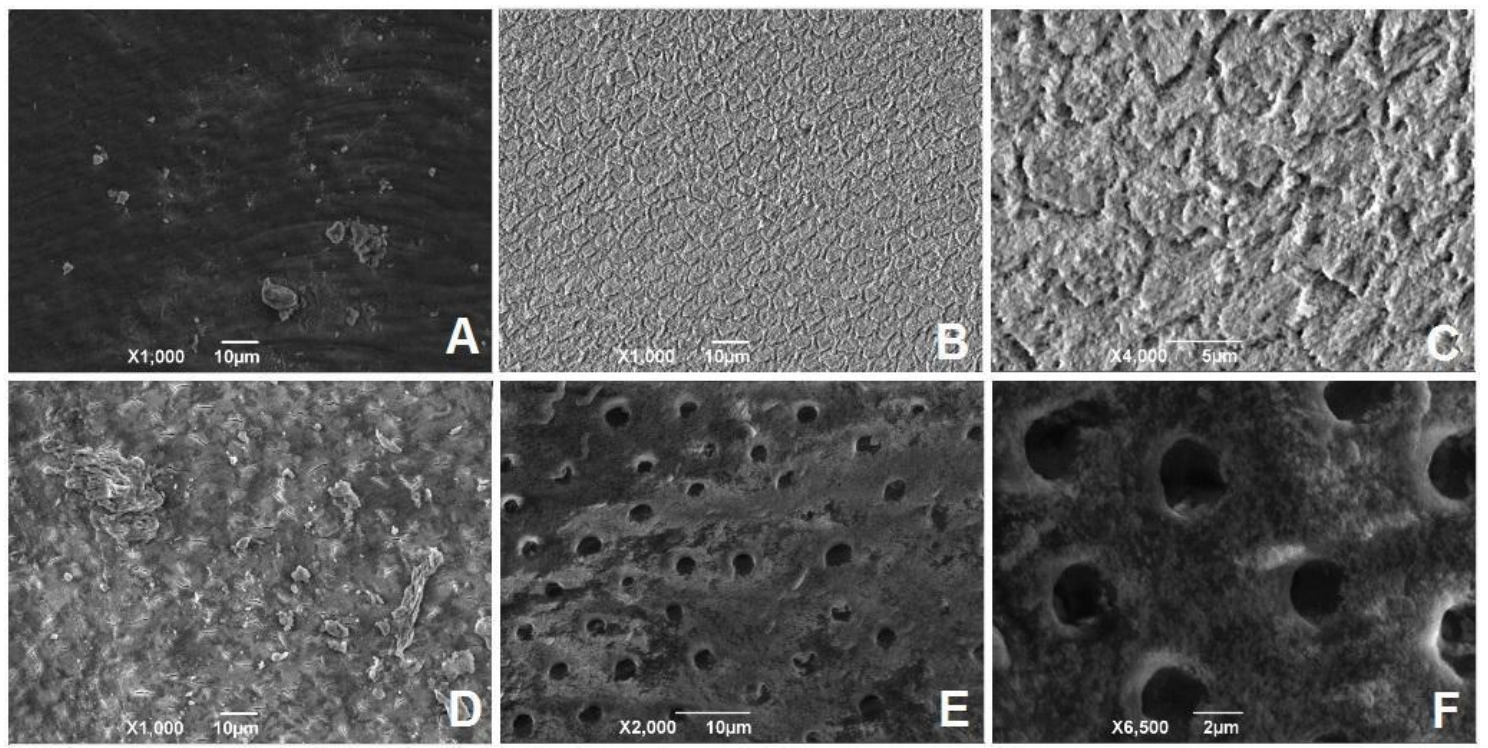

Figura 1: Grupo controle. A - Esmalte após preparo com alta rotação (Aumento de 1000x); B - Esmalte após preparo com alta rotação e condicionamento com ácido fosfórico a 37\% (Aumento de 1000x); $\mathbf{C}$ Esmalte após preparo com alta rotação e condicionamento com ácido fosfórico a 37\% (Aumento de 4000x); D - Dentina após preparo com alta rotação (Aumento de 1000x); E - Dentina após preparo com alta rotação e condicionamento com ácido fosfórico a 37\% (Aumento de 2000x); F - Dentina após preparo com alta rotação e condicionamento com ácido fosfórico a 37\% (Aumento de 6500x).

O esmalte condicionado pelo ácido fosfórico pode apresentar três padrões de condicionamento (SILVERSTONE et al., 1975). A superfície de esmalte condicionado pelo ácido fosfórico na Amostra 3 apresentou o padrão de condicionamento tipo II, onde a periferia dos prismas é removida, e o núcleo permanece intacto (figuras .1.B e 1.C). Entretanto, um dos maiores problemas do uso do ácido fosfórico separadamente do 
agente de união é a falha na adesão, pela disparidade entre a área que foi desmineralizada e onde o adesivo se infiltrou (FRASSETTO et al., 2016), como pode ser visto na figura 2.A. Isso é explicado pela baixa afinidade pelo colágeno que os monômeros resinosos apresentam (VAN MEERBEEK et al., 2003), o que pode causar o fenômeno de nanoinfiltração. Para combater este problema, surgiram os sistemas adesivos autocondicionantes, que não removem totalmente a smear layer, deixando os túbulos dentinários parcialmente obstruídos (Figura 2.B).

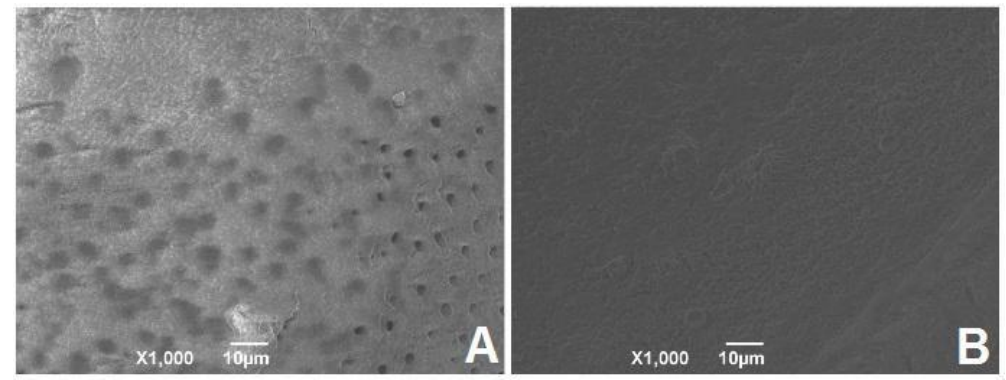

Figura 2: Tratamentos realizados nas superfícies de dentina preparadas com alta rotação (Aumentos de 1000x). A - Ácido fosfórico e sistema adesivo Single Bond Universal; B - Sistema adesivo Clearfil SE.

Mesmo formando uma camada híbrida menos espessa, em comparação aos adesivos convencionais, uma das explicações para o bom selamento dos autocondicionantes é a adesão química causada pelo 10-MDP, presente na maioria destes sistemas adesivos e dos universais (GRÉGOIRE; SHARROCK; PRIGENT, 2016).

O esmalte necessita de condicionamento ácido prévio quando se utiliza sistemas autocondicionantes, pois o padrão de desmineralização gerado é menos retentivo (Figura 3.B), quando comparado ao condicionamento com ácido fosfórico (Figura 3.A), causando uma menor resistência adesiva ao esmalte (PERDIGÃO; GERALDELI; HODGES, 2003).
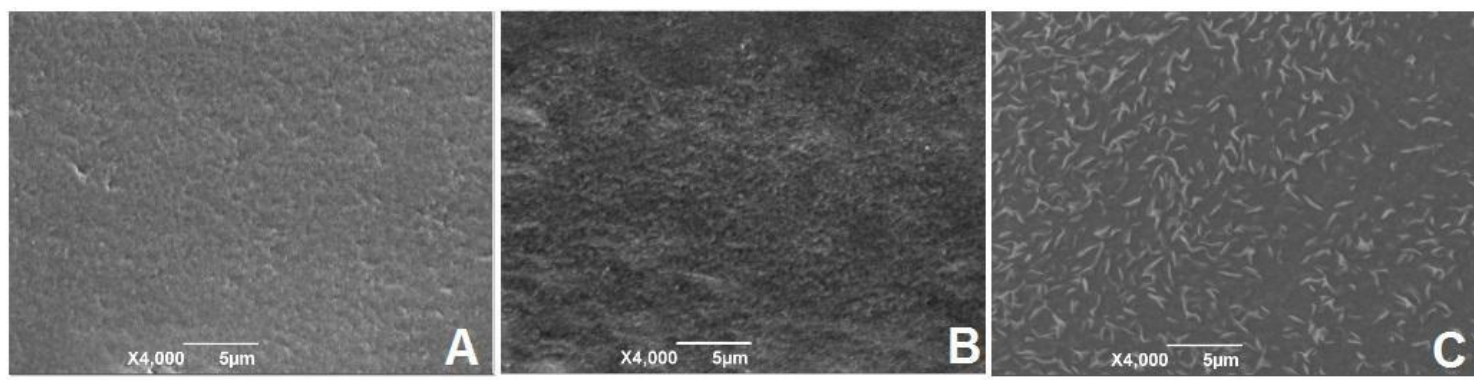

Figura 3: Tratamentos realizados nas superfícies de esmalte preparadas com alta rotação (Aumentos de 4000x). A -Ácido fosfórico a 37\% e sistema adesivo Single Bond Universal; B - Sistema adesivo Single Bond Universal; C - Ácido fosfórico a 37\% e sistema adesivo Clearfil SE.

\section{CONCLUSÃO}

Dentro da limitação deste estudo in vitro, é possível concluir que a utilização do ácido fosfórico é indispensável em esmalte, mesmo utilizando sistemas adesivos autocondicionantes ou universais; e que estes sistemas adesivos podem ser utilizados em dentina, sem a necessidade de condicionamento prévio, garantindo uma boa adesão neste substrato.

\section{REFERÊNCIAS}

BUONOCORE, M. G. A Simple Method of Increasing the Adhesion of Acrylic Filling 
Materials to Enamel Surfaces. Journal of Dental Research, v. 34, n. 6, p. 849-853, 9 dez. 1955.

COPPINI, E. K. et al. Influence of enamel acid-etching on mechanical properties and nanoleakage of resin composite after aging. Brailian Journal of Oral Sciences, v. 16, p. e17059, 2017.

FRANKENBERGER, R.; KRÄMER, N.; PETSCHELT, A. Long-term effect of dentin primers on enamel bond strength and marginal adaptation. Operative dentistry, v. 25, n. 1, p. 11-9, 2000.

FRASSETTO, A. et al. Mechanisms of degradation of the hybrid layer in adhesive dentistry and therapeutic agents to improve bond durability--A literature review. Dental materials : official publication of the Academy of Dental Materials, v. 32, n. 2, p. e41-53, fev. 2016.

GRÉGOIRE, G.; SHARROCK, P.; PRIGENT, Y. Performance of a universal adhesive on etched and non-etched surfaces: Do the results match the expectations? Materials science \& engineering. C, Materials for biological applications, v. 66, p. 199-205, 1 set. 2016.

INOUE, S. et al. Microtensile bond strength of eleven contemporary adhesives to enamel. American journal of dentistry, v. 16, n. 5, p. 329-34, out. 2003.

KHOROUSHI, M.; RAFIZADEH, M.; SAMIMI, P. Bond strength of composite resin to enamel: assessment of two ethanol wet-bonding techniques. Journal of dentistry (Tehran, Iran), v. 11, n. 2, p. 150-60, mar. 2014.

ODA, M.; MATOS, A. B.; LIBERTI, E. A. Morfologia da dentina tratada com substâncias dessensibilizantes: avaliação através da microscopia eletrônica de varredura.

Revista de Odontologia da Universidade de São Paulo, v. 13, n. 4, p. 337-342, dez. 1999.

PASHLEY, D. H.; MICHELICH, V.; KEHL, T. Dentin permeability: effects of smear layer removal. The Journal of prosthetic dentistry, v. 46, n. 5, p. 531-7, nov. 1981.

PERDIGÃO, J.; GERALDELI, S.; HODGES, J. S. Total-etch versus self-etch adhesive: effect on postoperative sensitivity. Journal of the American Dental Association (1939), v. 134, n. 12, p. 1621-9, dez. 2003.

SILVERSTONE, L. M. et al. Variation in the pattern of acid etching of human dental enamel examined by scanning electron microscopy. Caries Research, v. 9, n. 5, p. 373-87, 1975.

SZESZ, A. et al. Selective enamel etching in cervical lesions for self-etch adhesives: A systematic review and meta-analysis. Journal of dentistry, v. 53, p. 1-11, 2016.

TAKAMIZAWA, T. et al. Influence of different etching modes on bond strength and fatigue strength to dentin using universal adhesive systems. Dental materials : official publication of the Academy of Dental Materials, v. 32, n. 2, p. e9-21, fev. 2016.

VAN MEERBEEK, B. et al. Buonocore memorial lecture. Adhesion to enamel and dentin: current status and future challenges. Operative dentistry, v. 28, n. 3, p. 215-35, 2003. 